\section{MERMAC: A model and system for instructional test and questionnaire analysis*}

\author{
LAWRENCE M. ALEAMONI \\ University of Illinois, Champaign, Illinois 61820
}

An evaluation model was developed to aid the classroom instructor in teaching his course more effectively by providing him with the basic data upon which to make judgments about student abilities, course attitudes, grade distributions, test appropriateness, etc. The MERMAC system was designed so that each instructor could obtain the data in a usable format and also be able to provide relatively immediate feedback to the students taking an examination or filling out a course evaluation questionnaire. A description of the software system and its interface to the evaluation model is presented.
This paper begins with the assumption that what the student generally studies and learns tends to be the material that is tested, not necessarily the material that is presented. In addition, tests used in a course represent, in a very practical manner, the direction an instructor thinks the students should go, which, in turn, determines the emphasis that the students will place on the material treated by the test. Good tests can, therefore, orient student learning, while the development of the tests and the knowledge of student responses can help to improve instruction.

\section{DESCRIPTION}

The MERMAC system was designed to assist instructors and other test evaluators in developing valid and reliable tests, in addition to providing rapid and meaningful feedback to the instructor, evaluator, students, etc. The questionnaire portion of the system allows all who develop and use questionnaires to summarize data on attitudes, opinions, personality, etc., in an easily interpretable format.

MERMAC is made up of two sets of programs (see Fig. 1): (1) utility (data manipulation) programs, and (2) test and questionnaire analysis programs. The seven utility programs allow the user to copy, edit, match, merge, sequence, sort, and recode the input data. Generally, the purpose of these programs is to prepare the data for input to the test and questionnaire analysis programs. The six test and questionnaire programs allow the user to:

(1) Score item data and produce up to 40 subscores for each individual. Each item and response may be weighted to arrive at the scores. Any differently in each. An example of the SCDRE program output is presented in Fig. 2.

*The manual and system can be obtained by writing the University Press, University of Illinois, Urbana, Illinois 61801 . item may be included in more than one subscore and be weighted
(2) Take scores for a group of individuals and produce a frequency distribution and histogram, mean, median, standard deviation, Kuder-Richardson reliability, standard error of measurement, and Spearman-Brown prophesy for a reliability of .90 . In addition, individual raw scores, standard scores, and percentiles may be listed. Individual raw scores and standard scores can be weighted, summed, and the sum assigned a letter grade. All these data can be easily provided to the student. An example of the TQTAL program output is presented in Fig. 3.

(3) Return to each student a page containing his test score and a list of the items he missed with his responses and the correct responses. An example of the ERR $\emptyset R$ program output is presented in Fig. 4.

(4) Analyze his item data by

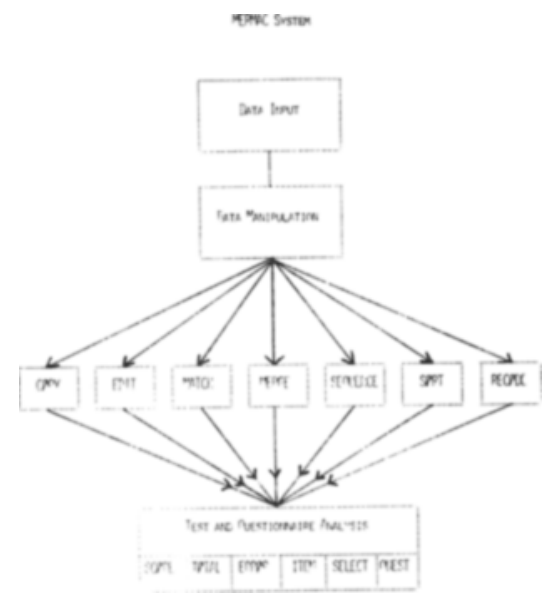

Fig. 1. The MERMAC system is presented in diagrammatic form, showing how input data is passed through the data manipulation programs before being input to the test and questionnaire analysis programs.

providing a plot of the percentage of individuals responding to the keyed response by fifths of the total score distribution. For each item alternative, the proportion of individuals responding, a point biserial correlation, and the number responding to each alternative by fifths is provided. An example of the ITEM program output is presented in Fig. 5

(5) Analyze his item data by using some external criterion rather than the keyed test score. The output format of

\begin{tabular}{|c|c|c|c|}
\hline Name & $\begin{array}{r}\text { Score Analysis } \\
\text { Score } 1\end{array}$ & Output & Total \\
\hline 262888459BRAMAN & 4 & 8 & 22 \\
\hline 111111111 ELMQUIST & 9 & 7 & 38 \\
\hline 316421537 EWOLDT & 10 & 10 & 48 \\
\hline 444432111 HEIKOF F & 11 & 10 & 40 \\
\hline $353410511 \mathrm{KOPCHELL}$ & 8 & 11 & 42 \\
\hline $340447477 \mathrm{LEE}$ & 9 & 14 & 53 \\
\hline 3614481 20MCK AY & 10 & 8 & 37 \\
\hline 330323281 NORREGAARD & 6 & 6 & 28 \\
\hline 777888888 OWEN & 8 & 12 & 46 \\
\hline 357417445 OWENS & 7 & 9 & 33 \\
\hline 331448166PEARSON & 6 & 11 & 43 \\
\hline 322407590 PLESKO & 5 & 10 & 32 \\
\hline 111100000 PLUTCHAK & 6 & 5 & 28 \\
\hline 343441821R ODELL & 10 & 14 & 50 \\
\hline 340448994ROTHBAUM & 13 & 11 & 51 \\
\hline 999990103SCALET'TA & 6 & 13 & 43 \\
\hline 328409897 STUCKMAN & 6 & 11 & $\mathbf{3 7}$ \\
\hline 347004156 SUTHER LAND & 6 & 9 & 27 \\
\hline O75449011SWICK & 6 & 9 & 27 \\
\hline 550761471TYMCHEK & 9 & 10 & 36 \\
\hline 341504514VALENZIA & 6 & 9 & 30 \\
\hline 327801815WARD & 10 & 14 & 46 \\
\hline
\end{tabular}

Fig. 2. A sample output of the SCQRE program is presented for 22 individuals. Their names, social security numbers, two-part scores on a 65 -item test, and the test total score appear on the output. Score 1 includes Items 1-15, Score 2 includes Items 16-20, and total includes Items 1-65. 


\begin{tabular}{|c|c|c|c|c|c|c|c|c|}
\hline \multicolumn{2}{|c|}{ SUMMARY OF TEST STATISTICS } & \multicolumn{7}{|c|}{ TEST FREQUENCY DISTRIBUTION } \\
\hline \multirow{2}{*}{ NUMBER OF I TEMS } & 15 & RAW & STANDARD & PER & & & CUM & \\
\hline & 365 & SCORE & SCORE & CENTI LE & PERCENT & FREQ & FREQ & Each \# Represents 2 Persons \\
\hline MEAN SCORE & & 14 & 931 & 99 & $0.6 \%$ & 1 & 173 & $\#$ \\
\hline \multirow[t]{2}{*}{ MEDIAN SCORE } & 3.23 & 13 & 889 & 99 & $1.2 \%$ & 2 & 172 & $\#$ \\
\hline & & 12 & 848 & 98 & $0.0 \%$ & 0 & 170 & \\
\hline \multirow[t]{2}{*}{ STANDARD DEVIATION } & 2.40 & 11 & 806 & 98 & $1.7 \%$ & 3 & 170 & $\# \#$ \\
\hline & & 10 & 764 & 97 & $0.6 \%$ & 1 & 167 & $\#$ \\
\hline \multirow[t]{2}{*}{ RELIABILITY (KR-21) } & 0.558 & 9 & 723 & 96 & $0.6 \%$ & 1 & 166 & $\#$ \\
\hline & & 8 & 681 & 95 & $0.6 \%$ & 1 & 166 & $\#$ \\
\hline \multirow[t]{2}{*}{ S.E. OF MEASUREMENT } & 1.60 & 7 & 639 & 95 & $4.0 \%$ & 7 & 164 & $\# \# \#$ \\
\hline & & 6 & 598 & 91 & $5.2 \%$ & 9 & 157 & \#\#\# \\
\hline POSSIBLE LOW SCORE & 0 & 5 & 556 & 86 & $10.4 \%$ & 18 & 148 & 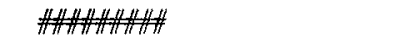 \\
\hline \multirow[t]{2}{*}{ POSSIBLE HIGH SCORE } & 15 & 4 & 514 & 75 & $19.9 \%$ & 33 & 130 & \#\#\#\#\#\#\#\#\#\#\# \\
\hline & & 3 & 473 & 56 & $22.5 \%$ & 39 & 97 & 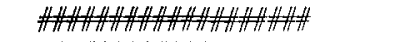 \\
\hline OBTAINED LOW SCORE & 0 & 2 & 431 & 34 & $20.8 \%$ & 36 & 58 & \#\#\#\#\#\#\#\#\#\#HAH\# \\
\hline \multirow[t]{2}{*}{ OBTAINED HIGH SCORE } & 14 & 1 & 389 & 13 & $10.4 \%$ & 18 & 22 & \#\#\#\#\#\# \\
\hline & & 0 & 348 & 2 & $2.3 \%$ & 4 & 4 & $\#$ \\
\hline \multirow{4}{*}{$\begin{array}{l}\text { NUMBER OF SCORES } \\
\text { BLANK SCORES } \\
\text { INVALID SCORES } \\
\text { VALID SCORES }\end{array}$} & 173 & & & & & & & \\
\hline & 0 & & & & & & & \\
\hline & 0 & & & & & & & \\
\hline & 173 & & & & & & & \\
\hline \multirow{5}{*}{\multicolumn{2}{|c|}{$\begin{array}{l}\text { "SPEARMAN-BROWN PROPHESY FOR- } \\
\text { MULA: IN ORDER FOR THIS TEST } \\
\text { TO OBTAIN A RELIABILITY OF .9O } \\
\text { IT MUST BE } 6.14 \text { LONGER. ( } 92 \\
\text { ADDITIONAL ITEMS)." }\end{array}$}} & & & & & & & \\
\hline & & & & & & & & \\
\hline & & & & & & & & \\
\hline & & & & & & & & \\
\hline & & & & & & & & \\
\hline
\end{tabular}

TOTAL TEST PROGRAM US ING SUMMING AND GRADING

\begin{tabular}{|c|c|c|c|c|c|c|c|c|c|c|c|c|c|c|c|c|c|c|}
\hline \multirow[b]{3}{*}{ NAME } & \multicolumn{6}{|c|}{ SECTION } & \multicolumn{6}{|c|}{063} & \multirow{2}{*}{\multicolumn{3}{|c|}{ TOTAL }} & \multirow{2}{*}{\multicolumn{2}{|c|}{ SUMMED STD }} & \multirow{3}{*}{$\begin{array}{l}\text { SCORE } \\
\text { PCT }\end{array}$} \\
\hline & & PART $-O$ & & & PART - TW & & & $R T-T H R$ & & & $A R T-F$ OU & & & & & & & \\
\hline & RAW & STAND & PCT & RAW & STAND & $\mathrm{PCT}$ & RAW & STAND & PCT & RAW & STAND & $\mathrm{PCT}$ & RAW & STAND & PCT & RAW & STAND & \\
\hline $\begin{array}{l}\text { 361443742ANDERBERG } \\
\text { GRADE IS E }\end{array}$ & 3 & 371 & 25 & 4 & 475 & 51 & 2 & 365 & 18 & 3 & 405 & 39 & 12 & 2322 & 7 & 39 & 328 & 7 \\
\hline
\end{tabular}

Fig. 3. A sample output of the TФTAL program is presented and consists of three parts. The first part consists of a summary of various test statistics. The second part is the distribution of scores which are ordered high to low. The third part, which is optional, is a list-out of one student's raw score, standard score, and percentile rank for each test included in the program, as well as the optional summed score and grade.

STUDENT ERROR REPORT

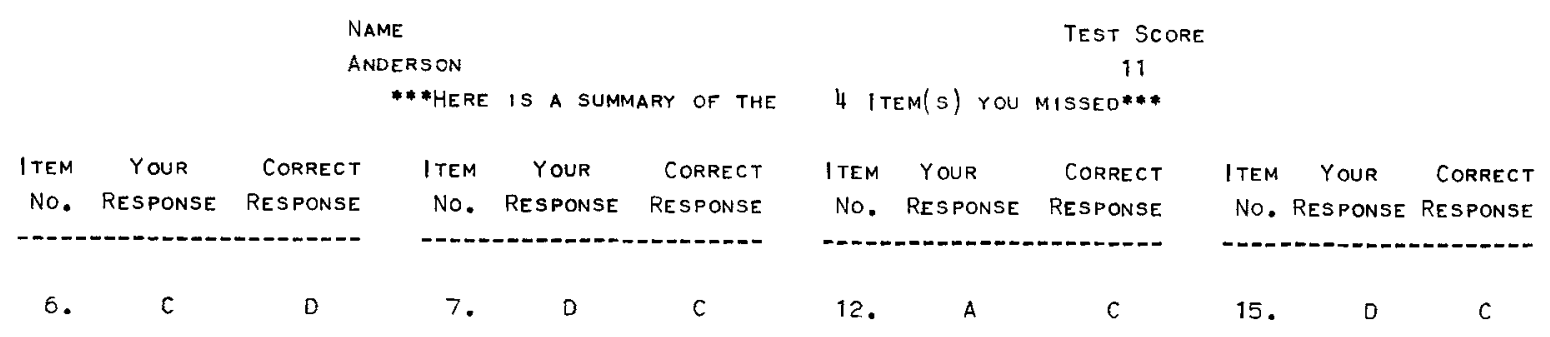

Fig. 4. A sample output of the ERR $\varphi R$ program is presented, showing an individual's calculated score and the incorrect responses with the corresponding correct responses for the four items missed. 
ITEM 4

DEPCENT GF CORRECT RESPONSE BY FIFTHS

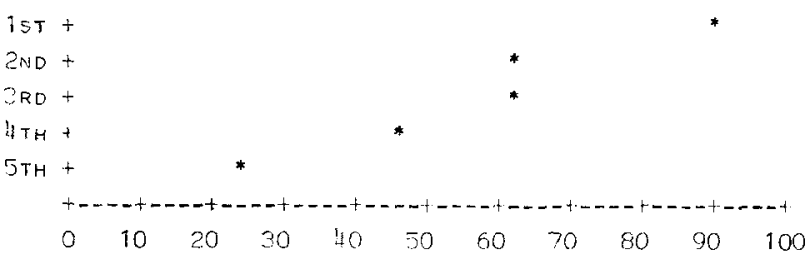

MATRIX OF RESPONSES BY FIFTHS D IS CORRECT PESFC:SE

$\begin{array}{rrrrrrc} & A & B & C & D & E & O M I T \\ \text { IST } & 1 & 2 & 0 & 39 & 1 & 0 \\ \text { IND } & 3 & 1 & 2 & 22 & 5 & 0 \\ 3 R D & 5 & 1 & 1 & 26 & 6 & 0 \\ \text { HTH } & 11 & 0 & 2 & 17 & 6 & 0 \\ \text { STH } & 4 & 1 & 5 & 6 & 6 & 0 \\ & & & & & & \\ \text { PROP } & 0.14 & 0.03 & 0.06 & 0.64 & 0.14 & 0.00 \\ \text { RPBI } & -0.21 & 0.01 & -0.18 & 0.37 & -0.19 & 0.00\end{array}$

Fig. 5. A sample output of the item statistics portion of the ITEM program is presented for one item. The plot of responses by fifths and the point biserial correlation (RPBI) indicate that it is an excellent item.

QUEST ANALYSIS OUTPUT

$$
\begin{aligned}
& \text { SEX DISTRIBUTION } \\
& \text { female male omit } \\
& \begin{array}{llll}
0.13 & 0.63 & 0.24
\end{array}
\end{aligned}
$$

$$
\begin{array}{ccccccc}
\multicolumn{7}{c}{\text { EXPECTED GRADE }} \\
\text { A } & \text { B } & C & \text { D } & \text { E } & \text { OMIT } \\
0.19 & 0.25 & 0.25 & 0.06 & 0.00 & 0.05
\end{array}
$$

$\begin{array}{cccc}A & 0 & \text { SD } & \text { OMIT } \\ 0.44 & 0.06 & 0.13 & 0.13 \\ 0.00 & 0.38 & 0.35 & 0.13 \\ 0.50 & 0.19 & 0.13 & 0.13 \\ 0.44 & 0.25 & 0.13 & 0.13 \\ 0.25 & 0.06 & 0.00 & 0.13 \\ 0.31 & 0.13 & 0.06 & 0.13 \\ 0.25 & 0.06 & 0.00 & 0.25 \\ 0.44 & 0.25 & 0.06 & 0.19 \\ 0.44 & 0.13 & 0.06 & 0.19 \\ 0.19 & 0.63 & 0.06 & 0.13\end{array}$

$\begin{array}{ccc}\text { BEST } & \text { MEAN } & 9.0 \\ \text { SA } & 3.93 & 0.95 \\ \text { SD } & 3.14 & 0.68 \\ \text { SA } & 2.57 & 1.01 \\ \text { SA } & 2.50 & 0.80 \\ \text { SA } & 3.57 & 0.70 \\ \text { SA } & 3.14 & 0.85 \\ \text { SA } & 3.50 & 0.81 \\ \text { SA } & 2.38 & 0.80 \\ \text { SA } & 2.92 & 0.89 \\ \text { SO } & 2.86 & 0.89\end{array}$

DECL

sequential access method (QSAM) support.

\section{APPLICATION}

Let us assume that the first basis of assisting the instructor in developing valid and reliable tests is also the basis for developing an evaluation model. The first step in the model, therefore, must be to provide assistance to the instructor in the determination of instructional objectives and the appropriate methods of measuring those objectives. This should also involve helping the instructor to write and select his test items. Figure 7 presents the interface of the model and the system.

The first step in the process which involves MERMAC would be to take the newly constructed or previously * used items and administer them to the class and then subject them to an item analysis, using either the keyed score

$$
\begin{array}{lcccccc}
\text {--SUBSCORE-- } & \text { ITEMS } & \text { RESP } & \text { MEAN } & \text { S.D. } & \text { REL } & N-01 \\
\text { TOTAL } & 10 & 0.85 & 2.95 & 0.89 & 0.92 & 6 \\
\text { PART-ONE } & 5 & 0.88 & 2.94 & 0.91 & 0.98 & 5 \\
\text { PART-TWO } & 5 & 0.82 & 2.95 & 0.85 & 0.90 & 6 \\
& & & & & &
\end{array}
$$

Fig. 6. A sample output of the QUEST program is presented for 16 individuals taking a 10-item questionnaire. The top part of the output contains descriptive information about the group (sex and expected grade). The center portion summarizes the responses to the questionnaire items which consisted of the following response scale: strongly agree (SA), agree (A), disagree (D), and strongly disagree (SD). The bottom portion indicates how many items were included in each subscore, the overall proportion of individuals responding to the items, the mean, standard deviation, reliability, and decile norm.

SELECT is identical to that of ITEM.

(6) Summarize item data from questionnaires or tests with no known correct answers by providing a frequency distribution of responses, a weighted mean, and a standard deviation for each item. In addition, subscores may be generated with means, standard deviation, split-half reliabilities, and percentage of individuals responding to the contributing items. It is also possible to assign deciles to the item and subscore means based on a table look-up. An example of the QUEST program output is presented in Fig. 6.

The MERMAC system is written in Basic Assembly Language (BAL) for both (1) IBM System/360, Models 40 and above, and (2) IBM System/370, Models 135 and above, which have operating system (OS) with queued

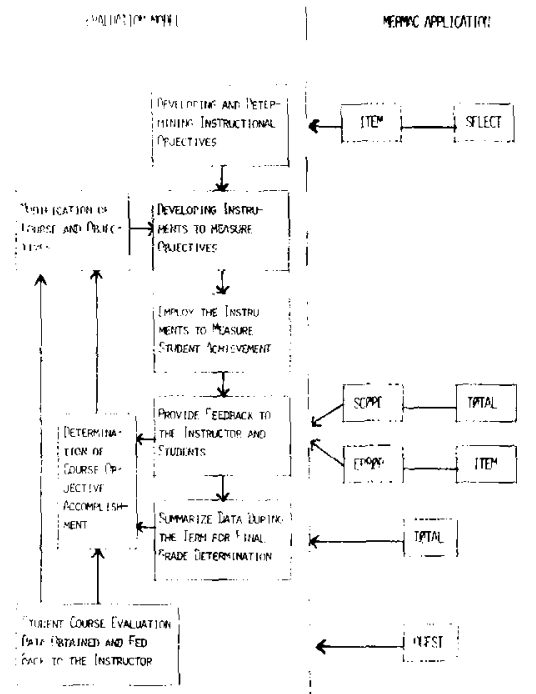

Fig. 7. A diagrammatic representation of the interface between the proposed evaluation model and the MERMAC system is presented, showing where the specific MERMAC programs should enter into the decision considerations of the model. 
or an external criterion score. Through the use of the item analysis statistics and the content knowledge of the instructor, a reliable and valid set of questions can be generated.

Once the final set of questions has been obtained, then the instructor is ready to have them administered, scored, and analyzed to determine what number of subscores exist or should be constructed. The instructor could now expect to receive score distributions on the total test or subscores for students in his course. These score distributions would allow him to determine how well the students were accomplishing his course objectives and what grades should be assigned. At the same time, the students can be made aware of their performance on specific questions and in comparison to their classmates through the student error reports.

The instructor should discuss with the students those items most frequently missed and then provide them with a mimeographed sheet outlining the topical areas covered by the test questions, showing how they fit into his scheme or course objectives. By allowing the students only to take the mimeographed sheet along with their student error reports, the instructor is able to help the students identify their weakest areas and concentrate on improving them rather than memorizing the correct answer to each specific question posed. In addition, this allows the instructor to begin building a secure, reliable, and valid item bank for use later in that course or in other courses.

Once an instructor has developed the objective tests, term papers, laboratory exercises, etc., to be used in his course, he can now use the summing and grading option of the TФTAL program to accumulate and weight the scores and grades he assigns. This not only relieves the instructor of the time-consuming clerical operations involved, but also gives him a more objective method of combining the scores and grades assigned. In addition, each student can be provided with his complete record of performance during the course, along with his final grade.

In order to satisfy the second basis of returning results to the instructor and students in the fastest possible time, particular types of hardware and support staff are needed. The hardware should consist of a keypunch, an optical scanner, and IBM 360 system Model 40 or above. The support staff could consist only of individuals capable of operating the keypunch and optical scanner, assuming that each institution has a staff available to maintain the computer operation.
The only part of the proposed model that has not been dealt with is the questionnaire analysis. The QUEST program provides a means of collecting student attitudes and opinions toward a course and instructor, analyzing them, comparing the results to normative data, and then returning the results to the instructor. An example of this would be the Illinois Course Evaluation Questionnaire (CEQ) (Spencer \& Aleamoni, 1970), which yields responses to 50 items and six subscores (general course attitude, method of instruction, course content, interest and attention, instructor, and specific items). The subscore can then be compared to norms developed for different courses, course levels, departments, colleges, rank of instructor, etc. The instructor can also obtain results on any items that he may wish to generate.

Questionnaire data, in particular course evaluation data, can also help the instructor in diagnosing his course for possible changes in the (1) method of instruction, (2) course content, (3) personal delivery, (4) types of tests, (5) instructional materials, etc.

\section{REFERENCE}

SPENCER, R. E., \& ALEAMONI, L. M. A student course evaluation questionnaire. Journal of Educational Measurement, 1970, 7, 209-210. 